\title{
Pediatric neurology and epilepsy care in low-middle income countries: Importance of collaborative efforts and active involvement of local leaders
}

\author{
Jorge Vidaurre ${ }^{1}$, Dave Clarke ${ }^{2}$, Mary C. Spiciarich $\mathrm{MD}^{3}$, Jules C. Beal MD³ ${ }^{3}$, Solomon L. Moshé \\ $\mathrm{MD}^{3}$ \\ ${ }^{1}$ Nationwide Children's Hospital; ${ }^{2}$ Division of Pediatric Neurology, Texas Children's Hospital, Baylor \\ College of Medicine, Houston, Texas; ${ }^{3}$ Department of Neuroscience and Department of Pediatrics. \\ Montefiore/Einstein Epilepsy Management Center, Albert Einstein College of Medicine and \\ Montefiore Medical Center, Bronx, New York
}

Corresponding author: Jorge Vidaurre; Email: jorge.vidaurre@nationwidechildrens.org

do:

https://doi.org/10.17724/jicna.2019.143

Received: 06 April 2018

Accepted: 16 Nov 2018

\begin{abstract}
The lack of access to proper neurological care is a significant problem in low-to middle-income countries.The development of local training programmes, development of national programmes in collaboration with medical colleges and creation of online educational material are examples of various initiatives currently being implemented across the world.Collaborative efforts between medical societies and these local groups will be vital to the success of these initiatives, and for the improvement of access to paediatric neurology care in these underserved areas.
\end{abstract}

Kewords: global neurology, icna, icnapedia, epilepsy.

(C) Vidaurre J; licensee JICNA

\section{Introduction}

The lack of access to proper neurological care is a significant problem in low- to middle-income countries. The World Health Organization (WHO) recommends a ratio of one neurologist per 100,000 inhabitants. In the USA, there is approximately one neurologist per 26,200 people [1]. In African countries, this ratio ranges from $1: 711,856$ to 1:5,099,908 [2]. In Latin America and the Caribbean, the ratio is about 1.18:100,000 with most neurologists concentrated in large urban areas [3].

From a global perspective, a total of $270,000,000$ people live in countries where there are fewer than five neurologists [2], while some nations have no neurologists at all. Updated statistics from the WHO showed a substantial difference in access to neurological care in different regions of the world. Low-income countries have an average ratio of 0.1 neurologist per 100,000 inhabitants (0.04:1000,000 in the African region) compared to $7.1: 100,000$ in high-income countries [4].

The situation in paediatric neurology is even more complex due to the small number of formally trained paediatric neurologists worldwide. Because of this challenge, paedi- atric neurological care in low- to middle-income countries is frequently delivered by primary care providers or other healthworkers with limited neurological training.

Despite a recent decrease in communicable diseases observed in low- to middle-income countries 1 , the prevalence of neurological conditions, such as perinatal injuries, cerebral palsy, traumatic brain injury and neuro-infections remains high. Neurocysticercosis, tuberculosis and malaria contribute to the increase in the number of seizures and patients with epilepsy, increasing the demand for neurological care in endemic regions.

The main causes of cerebral palsy are birth complications and postnatal infections, compared to higher-income countries, where the main etiology is prematurity. The rate of kernicterus is also high and contributes to the high incidence of cerebral palsy. The treatment gap for these children [5] [6] is widened further by the limited access to care and lack of adaptive equipment.

Other neurodevelopmental disorders, such as autism spectrum and attention deficit hyperactivity, as well as intellectual disability are highly prevalent in low-income countries [7]. These disorders are often managed by primary 
paediatric healthcare services, and the medical personnel responsible for diagnosis and treatment usually lacks appropriate training [8].

\section{Limitations to delivery of care in resource-limited countries}

Paediatric neurologists and local medical personnel practicing in low-resource settings face multiple challenges. Access to neuroimaging and specialised neurophysiological testing, such as EEG (electroencephalography), is typically concentrated in single centres, usually located in larger cities [1].

Data about availability of neurodiagnostic tests is scant. A recent survey showed that availability of EEG and EMG (electromyography) correlated with per capita income, as did CT (computed tomography) scans and MRI (magnetic resonance imaging). Patients in lower-income countries also appear to have a longer waiting time for the performance of these tests [9].

Most neurodiagnostic tests are affordable for $>70 \%$ of the total population in America and Europe, but the lowest affordability is in Africa and Southeast Asia. In these regions, the majority of tests are affordable by $<50 \%$ of the total population [9]. These factors likely contribute to the inappropriate diagnosis and treatment of neurological disorders in low-income areas.

There is frequently a limited supply of medications, especially AEDs (antiepileptic drugs). An insufficient supply of AEDs was reported in 53\% of countries globally according to the WHO (2015). About $48 \%$ of low-income countries have at least one anticonvulsant available at hospital level vs $94 \%$ of high-income countries [10].

Formularies usually carry early generation AEDs, such as phenobarbital, carbamazepine, phenytoin and valproic acid. Even when these drugs are available, they are often prohibitively expensive in low- to middle-income countries, despite being relatively inexpensive elsewhere [11].Inconsistent availability of any single drug limits the patient's ability to remain adherent and increases the risk of breakthrough seizures [12]. A Pan American Health Organization (PAHO) summary showed that only $62 \%$ of the countries in Latin America and the Caribbean had AEDs consistently available throughout the year at primary healthcare facilities[3].

Doctors and local health workers working in public hospitals usually have suboptimal salaries and high workloads. This may force physicians to work at least part-time in private practices; however the services provided in private settings are extremely expensive and inaccessible for the majority of the population[3]. Moreover, many local governments do not invest in the training of medical personnel interested in paediatric neurology and this may result in a poor retention rate [13]. Doctors seeking training in Western institutions may not return to their home countries.

Navigating these healthcare systems can also be very challenging for families living in rural areas. In particular, it may be difficult to access the regular follow-up care that is needed in the management of chronic conditions. Patients and families in need of such services may lack the economic resources to cover costs of transport, medications or testing. This is due to the fact that much of healthcare financing in these regions is covered by out of pocket payments without governmental support [14].

\section{Possible solutions}

The development of local training programmes is crucial to improve delivery of neurological care in countries with limited resources. Training of primary care personnel interested in paediatric neurology should be a priority. This is especially important in countries with few or no formally trained paediatric neurologists. Training modules should focus on diagnosis and treatment of common disorders and on the identification of complex neurological conditions that need referral to subspecialty centres, if available.

Ideally, this training should be provided by local or regional centres of excellence with the capacity to provide subspecialty care. Programmes such as the African Paediatric Fellowship Programme' in South Africa aim to increase the number of African child neurologists, but there are budget limitations [13]. Supporting these programmes and promoting the creation of training centres in different regions is essential to their success.

Local medical centres of excellence or tertiary care hospitals can play a crucial role not only in the training of medical personnel, but also in the development of research projects of interest to the local community. This is important for the gathering of epidemiological data and implementation of specific interventions aimed at reducing the gap in medical treatment. Large, regional medical centres can develop telemedicine projects to reach underserved populations [15] [16].

These centres can work with communities and the government in the creation of public health policies. Tertiary centres in India, such as the All India Institute of Medical Sciences, have developed useful diagnostic instruments which can be used for primary care providers, and have created very comprehensive models of collaboration with governmental agencies, healthcare providers and families, in order to improve diagnosis and treatment of neurodevelopmental disorders [8] [17] [18].

Development of national programmes in collaboration with medical colleges is important in order to create effective projects [19]. Joint efforts between local leaders and national or international medical societies and institutions also offer a great opportunity to facilitate training and develop high-impact educational projects. The active involvement of local leaders is crucial for the development of programmes that are relevant to the specific regions and to ensure long term sustainability and acceptance by the community. A continuous medical education programme can support formal local training though annual courses or work- 
shops.

The creation of online educational material is another training alternative. Websites and training modules can be periodically updated to reflect the most current evidencebased practice and standard of care. Online courses are a very useful tool for local physicians who otherwise lack the economic resources to travel to specialised centres, locally or abroad. The International Child Neurology Association (ICNA) offers and provides a series of free online training courses (available at ICNApedia.org). Cooperative efforts between medical societies could strengthen these valuable resources.

\section{Collaborative efforts and engagement of local leaders}

Multi-society collaboration is possible and essential for produce high-impact programmes. One such example is the partnership between the ICNA and the Child Neurology Society (CNS). Both societies collaborated in the planning and creation of multiple educational activities in different regions, including South America, Central America, the Caribbean, Asia and Africa. These symposiums and training workshops were planned with direct involvement of local Paediatric Neurologists or Paediatricians and were adapted to the local needs [20].

Another example is the collaboration between the International League Against Epilepsy (ILAE), the International Bureau for Epilepsy (IBE), and the WHO in the Global Campaign Against Epilepsy. These organisations have worked together to raise epilepsy awareness and to support national and regional organisations in promoting services for people with epilepsy. By organizing regional conferences, educational materials, and large scale interventional 'demonstration projects', they have been able to improve epilepsy legislation and increase funding for research and treatment in previously underserved regions [21] [4].

Collaborative efforts in the Caribbean region also illustrate the importance of partnership to develop long-term, sustainable programmes. The Caribbean is a diverse region with over 7,000 islands grouped by history or affiliation into 28 separate countries or territories. Populations range from over 11 million in Cuba to approximately 5,000 in Monserrat. Most of the islands in the Caribbean are Englishspeaking, but other languages such as Spanish, Dutch and French are spoken as well.

Year-round neurological services are available in only four of the 20 Anglo-Caribbean or English-speaking islands and there is limited access to neuroimaging and EEG. The availability of antiepileptic drugs is also variable in the different regions.

Multiple educational activities and training programmes have been developed in the region with local leaders working together with national and international societies, including the ILAE (International League Against Epilepsy), ICNA (International Child Neurology Associa- tion), CNS (Child Neurology Society), Jamaican League against Epilepsy and Epilepsy Society of the Caribbean. Advocacy and engagement of local government has been an important factor in the success of such programmes, with the focus of these joint efforts aimed at improving diagnosis, and reducing treatment gaps and stigma in patients with epilepsy [22] [23].

Medical societies can also facilitate joint efforts between local leaders in different regions. In 2013, the ICNA supported doctors from 22 African countries meeting to discuss challenges in the diagnosis and management of children with cerebral palsy [24].

\section{Summary}

Lack of access to paediatric neurological care is a significant problem in low- to middle-income countries, often due to a combination of factors. Frequently, there may be insufficient or inadequately trained medical personnel, inconsistent availability of medications, lack of adequate facilities and equipment, and/or difficulty in accessing follow-up care for patients and families.

The political and socio-economic environment of each country and the low number of formally trained paediatric neurologists are problems that these regions will continue to face, at least for the short term. There is a need for international outreach programmes and educational activities to produce a positive impact in the neurological care provided in these regions. They will have to focus on the training of doctors and healthworkers in paediatric neurology, and on making neurological conditions a priority in terms of the financing, research, and improving the access to care. In some instances, online training modules may help to meet these needs. Partnership with local leaders will be essential. This may include the involvement of local and national governments and advocacy groups, as well as local physicians and other healthworkers, and, in some cases, traditional healers.

Collaborative efforts between medical societies and these local groups will be vital to the success of these initiatives, and for the improvement of access to paediatric neurology care in these underserved areas.

\section{Competing interests}

The authors are not aware of any financial or non-financial competing interests which affect the content of this report.

\section{Authors' contributions}

All the authors contributed to data collection and also critically reviewed the manuscript. The final version of the manuscript was approved by all the authors.

This is an Open Access article distributed under the terms of the Creative Commons Attribution License 
(http://creativecommons.org/licenses/by/4.0), which permits unrestricted use, distribution, and reproduction in any medium, provided the original work is properly credited. The Creative Commons Public Domain Dedication waiver (http://creativecommons.org/publicdomain/zero/1.0/) applies to the data made available in this article, unless otherwise stated.

Cite this article as:

Vidaurre J, Clarke D, Spiciarich M, Beal J, Moshé S. Pediatric neurology and epilepsy care in lowmiddle income countries: Importance of collaborative efforts and active involvement of local leaders. JICNA [Internet]. 2019Aug.26;1(1). Available from: https://jicna.org/index.php/journal/article/view/jicna2018-143

\section{References}

[1] Bearden DR. Pediatric Neurology in Resource-Limited Settings: a Systematic Review. Current Pediatrics Reports. 2018 mar;6(1):34-39. Available from: http: //link.springer.com/10.1007/s40124-018-0155-x.

[2] Bower JH, Zenebe G. Neurologic services in the nations of Africa. Neurology. 2005 feb;64(3):4125. Available from: http://www.ncbi.nlm.nih.gov/ pubmed/15699367.

[3] Pan American Health Organization (PAHO/WHO). Report on Epilepsy in Latin America and the Caribbean. Washington, DC: PAHO, 2013. The Pan American Health Organization; 2013. Available from: https://www.paho.org/hq/dmdocuments/ 2014/epilepsy-ENG-final.pdf.

[4] World Health Organization. Global burden of epilepsy and the need for coordinated action at the country level to address its health, social and public knowledge implications: draft resolution proposed by Maldives, People's Republic of China and Russian Federation; 2015. Available from: https://apps.who.int/iris/ handle/10665/251859.

[5] Bearden D, Ciccone O, Patel A. Global Health: Pediatric Neurology. Seminars in Neurology. 2018 apr;38(02):200-207. Available from: http://www.thieme-connect.de/DOI/DOI?10.1055/ s-0038-1649336.

[6] Donald KA, Samia P, Kakooza-Mwesige A, Bearden D. Pediatric cerebral palsy in Africa: a systematic review. Seminars in pediatric neurology. 2014 mar;21(1):305. Available from: http://www.ncbi.nlm.nih.gov/ pubmed/24655402.

[7] Arora NK, Nair MKC, Gulati S, Deshmukh V, Mohapatra A, Mishra D, et al. Neurodevelopmental disorders in children aged 2-9 years: Population-based burden estimates across five regions in India. PLoS medicine. 2018;15(7):e1002615. Available from: http: //www.ncbi.nlm.nih.gov/pubmed/30040859http: //www.pubmedcentral.nih.gov/articlerender.fcgi? artid=PMC6057634.

[8] Gulati S. Neurodevelopmental disorders: The Journey, the dreams and their realization. Ann Natl Acad Med Sci (India). 2017;53(1):30-5.

[9] McLane HC, Berkowitz AL, Patenaude BN, McKenzie ED, Wolper E, Wahlster S, et al. Availability, accessibility, and affordability of neurodiagnostic tests in 37 countries. Neurology. 2015 nov;85(18):161422. Available from: http://www.ncbi.nlm.nih.gov/ pubmed/26446063http://www.pubmedcentral.nih. gov/articlerender.fcgi? artid=PMC4642148.

[10] WHO and the World Federation of Neurology. ATLAS Country Resources for Neurological Disorders. 2nd ed.; 2017. Available from: https://www.who.int/mental\{_\}health/neurology/ atlas $\left\{\_\right.$second $\left\{\_\right.$\}edition/en/.

[11] Cameron A, Bansal A, Dua T, Hill SR, Moshe SL, Mantel-Teeuwisse AK, et al. Mapping the availability, price, and affordability of antiepileptic drugs in 46 countries. Epilepsia. 2012 jun;53(6):962-9. Available from: http://www.ncbi.nlm.nih.gov/pubmed/ 22432967.

[12] Caraballo R, Fejerman N. Management of epilepsy in resource-limited settings. Epileptic disorders : international epilepsy journal with videotape. 2015 mar;17(1):13-8; quiz 18. Available from: http:// www.ncbi.nlm.nih.gov/pubmed/25635346.

[13] Wilmshurst JM, Badoe E, Wammanda RD, Mallewa M, Kakooza-Mwesige A, Venter A, et al. Child neurology services in Africa. Journal of child neurology. 2011 dec;26(12):1555-63. Available from: http: //www.ncbi.nlm.nih.gov/pubmed/22019842http: //www.pubmedcentral.nih.gov/articlerender.fcgi? artid=PMC3672989.

[14] Mills A. Health care systems in low- and middleincome countries. The New England journal of medicine. 2014 feb;370(6):552-7. Available from: http://www.ncbi.nlm.nih.gov/pubmed/24499213.

[15] Konanki R, Gulati S, Prasad K, Saini L, Pandey RM, Paul VK. Comparison of telephone with face to face consultation for follow up of Neurocysticercosis. Epilepsy research. 2018;145:110-115. Available from: http://www.ncbi.nlm.nih.gov/pubmed/29936301.

[16] NM S, Konanki R, Singh M, Saini L, Sondhi V, Jauhari P. Telephonic follow for chronic childhood neurological disorders: A Teach and Treat Initiative. Neurology. 2018;90(15 Supplement):S28. 001. 
[17] Gulati S, Patel H, Chakrabarty B, Dubey R, Arora NK, Pandey RM, et al. Development and validation of AIIMS modified INCLEN diagnostic instrument for epilepsy in children aged 1 month-18 years. Epilepsy research. 2017;130:64-68. Available from: http:// www.ncbi.nlm.nih.gov/pubmed/28157600.

[18] NM S, Sondhi V, Chakrabarty B. Comprehensive Neurodevelopmental Care: Initiatives to empower health care professionals and care givers in resource constrained settings. Neurology. 2018;90(15 Supplement):P3:156.

[19] Tripathi M, Jain DC, Devi MG, Jain S, Saxena V, Chandra PS, et al. Need for a national epilepsy control program. Annals of Indian Academy of Neurology. 2012 apr;15(2):89-93. Available from: http: //www.ncbi.nlm.nih.gov/pubmed/22566719http: //www.pubmedcentral.nih.gov/articlerender.fcgi? artid=PMC3345606.

[20] Vidaurre J, Clarke D, Kija E, Chugani H, Moshé SL. The Role of National and International Neurology Societies in Global Health. Pediatric neurology. 2018;81:35. Available from: http://www.ncbi.nlm.nih.gov/ pubmed/29525339.

[21] Moshé SL. The International League Against Epilepsy at the threshold of its second century: Challenges and opportunities. Epilepsia. 2009 dec;50(12):250813. Available from: http://www.ncbi.nlm.nih.gov/ pubmed/19824896.

[22] Melbourne-Chambers R, Clarke D, Gordon-Strachan G, Tapper J, Tulloch-Reid MK. The UWIMONA Pediatric Epileptic Seizure Screening Questionnaire was equivalent to clinical assessment in identifying children with epilepsy. Journal of clinical epidemiology. 2015 sep;68(9):988-93. Available from: http://www. ncbi.nlm.nih.gov/pubmed/25861709.

[23] Krauss G, Sandy S, Corbin DOC, Bird-Compton J, Jack F, Nelson B, et al. Epilepsy care in the southern Caribbean. Epilepsy \& behavior : E\&B. 2015 oct;51:267-72. Available from: http://www.ncbi.nlm. nih.gov/pubmed/26312988.

[24] Donald KA, Kakooza AM, Wammanda RD, Mallewa M, Samia P, Babakir H, et al. Pediatric Cerebral Palsy in Africa: Where Are We? Journal of child neurology. 2015 jul;30(8):963-71. Available from: http://www. ncbi.nlm.nih.gov/pubmed/25296926. 